\title{
ORAL PRESENTATION DIFFICULTIES - EXPERIENCE OF STUDENTS AT A POLYTECHNIC IN SARAWAK
}

\author{
Marcus Gee Whai Kho ${ }^{1}$ \\ Nur Syafiqa Aqiera Binti Abdullah ${ }^{2}$ \\ General Studies Department \\ Politeknik Kuching Sarawak \\ Lai-Mei Leong ${ }^{3}$ \\ School of Educational Studies \\ Universiti Sains Malaysia \\ ${ }^{1}$ marcus.k@poliku.edu.my \\ 2n.syafiqa@poliku.edu.my \\ 3Imleong@usm.my
}

\begin{abstract}
This study investigates areas of oral presentation difficulties experienced by students at a polytechnic in Sarawak. The participants of this study were 223 engineering and commerce students. The data were gathered through questionnaires and interviews. Findings from the data analysis show that the topmost predicament of the students in dealing with oral presentation is delivery, especially where language usage and anxiety management are concerned. Another aspect of the findings is that engineering students differ significantly from commerce students in coping with oral presentation difficulties such as preparation, organisation and delivery.
\end{abstract}

Keywords: academic oral presentation difficulties, polytechnic students, Malaysia

\section{Introduction}

In Malaysia, graduate unemployment has been attributed to poor communication skills of graduates. An issue which has become a major concern in many Malaysian tertiary education institutions is concerning the large number of graduates who graduate with excellent results but remain unemployed. Some of the graduates are no doubt very good technically, but they are unable to express their ideas well. They are not able to communicate in English proficiently; they have difficulties in pronouncing words properly and using grammar correctly.

The industry feedback generally shows that Malaysian graduates do not have good communication and presentation skills. The reported main complaint from prospective employers is local graduates' "lack of communication skills, 
especially to communicate in English" (Hanafi Zaid \& Kamarudin, 2011, p. 2). Besides, anxiety and fear of making mistakes prevent them from making efforts to speak in English (Hanafi Zaid \& Kamarudin, 2011). Another study, Singh and Choo (2012) also showed similar perceptions of the wanting English language proficiency skills of graduate employees by employers in the Malaysian manufacturing industry. They opine that some of the employees have poor written and oral communication skills, which affect their work performance. A study by Hamidah Yamat @ Ahmad (as cited in Singh \& Choo, 2012) showed that some final year undergraduates were unsure of their language competency; in that they were unsure whether their language command was sufficient for them to undertake their particular fields of occupation or even to be employed in the first place.

Before they enter the workplace, students' performance in oral presentations in colleges and universities already indicate that they are not well prepared for effective communication. The students often feel frustrated and intimidated each time when they are assigned oral presentations; this is especially the case when they are dealing with research matters and require communication skills for a successful presentation (King, 2002). Besides, it is also stressful for students who are not fluent in English but are expected to speak in the target language, especially during their English lessons (Abdullah, \& Abdul Rahman, 2010). They often leave the task of making oral presentations to the more proficient members of their group. However, students cannot avoid oral presentation tasks just because they lack the relevant skills or confidence. It is important for students to master oral presentation skills as they may need to use these skills when they enter the working world, such as attending a job interview or presenting a paper to a group of colleagues or superiors in a meeting.

College and university students should be taught oral presentation skills as these provide opportunities for them to hone their public speaking skills and develop stage confidence when they stand before an audience. Students are required to develop their communication competence in order to achieve this speaking ability. Yusoff (2010) stated that students' communication competence "is demonstrated through their ability to deliver a clear, convincing oral presentation to a specific audience, in this case their industry and faculty supervisors, in a way that elicits response, understanding, appreciation, assent, or critical inquiry" (p. 103). For college and university lecturers to have the right focus when teaching students oral presentation skills, it is important to find out the specific difficulties students encounter in relation to oral presentations.

Some studies have been conducted to investigate students' difficulties in delivering oral presentations. Kakepoto, Habil, Omar and Said (2012) carried out a study on factors that influenced effective oral presentation performance of engineering students. The results indicate that the main factors that hinder the engineering students from delivering oral presentations effectively are poor presentation skills, poor confidence and nervousness. Even though the engineering students were aware of the oral presentation delivery skills, they did not use appropriate delivery skills when giving oral presentations. This is probably due to a lack of practice among the students (Habil, \& Ab. Rahman, 2010). In the context of 
language anxiety, Kakepoto et al.'s (2012) results indicate that communication anxiety prevented the engineering students from making effective presentations.

Other studies have identified fear of communication apprehension as the main cause of anxiety besetting students making oral presentations. Studies conducted by El Enein (2011), Nguyen Thi Van (2010) and Chen (2009) found that the common challenge in oral presentation encountered by the tertiary education students is low level of language proficiency such as fluency, inaccurate pronunciation, lack of vocabulary and grammar inaccuracy. Moreover, the students also encountered difficulties in coping with psychological factors such as lack of confidence and fear of making mistakes. These problems are probably due to a lack of rapport between students and their lecturers, coupled with inadequate practice which adds to their limitations of language proficiency and communication apprehension.

Thus far, research has identified various difficulties related to oral presentations have been on tertiary students (Abdullah \& Abdul Rahman, 2010;I Chen, 2009; El Enein, 2011; Habil \& Ab Rahman, 2010; Hanafi Zaid \& Kamarudin, 2011; Kakepotp, habil, Omar, \& Said, 2012; Mahfoodh, 2014; Nguyen Thi Van, 2010; Yusoff, 2010) but less is known about the oral presentation difficulties of college (Chen, 2009) and polytechnic students (Zainuddin \& Selamat, 2012) whose academic training is more skill-based. The employers in Zainuddin and Selamat's (2012) study on efficacy of polytechnic students' interpersonal communication skills are concerned that the polytechnic graduates have "great difficulties in communicating effectively at work despite having excellent technical knowledge in their areas" ( $p$. 78). Further research is needed to better understand the specific difficulties faced by polytechnic students in making oral presentations, and the findings would also help lecturers in having the right focus when they teach oral presentation skills.

The purpose of this study is to investigate academic oral presentation difficulties faced by commerce and engineering students at a polytechnic in Sarawak.

\section{Theoretical Background}

The theoretical framework used in this study is language anxiety which comprises communication apprehension, test anxiety and fear of negative evaluation (Horwitz, Horwitz, \& Cope, 1986).

The first aspect of language anxiety is communication apprehension, which is defined as an "individual's level of fear or anxiety associated with either real or anticipated communication with another person or persons" (McCroskey, 1977, p. 78). Some students find giving an oral presentation a difficult task because of their inner fears. Students are afraid of making mistakes, criticism or rejection from the audience; they are worried they may forget what they want to say. All these fears are known as communication apprehension.

The second aspect of language anxiety is test anxiety is defined as "an apprehension over academic evaluation which is a fear of failing in test situations" (Horwitz \& Young, as cited in Joy, 2013, p. 2). They may become too concerned and start thinking that they will never be able to pronounce a word correctly or give a 
good presentation (Horwitz et al., 1986). Students who encounter test anxiety often put impractical demands on themselves and feel that anything less than a perfect test performance is a failure. As a result, they are unable to focus and become nervous during presentations.

The third aspect of language anxiety is fear of negative evaluation which is defined as "the apprehension and distress arising from concerns about being judged despairingly or hostilely by others" (Carleton, McCreary, Norton \& Asmundson, 2006 , p. 297). Students who encounter the fear of negative evaluation often feel worried when they are required to do oral presentations in English as they fear getting low marks from their lecturers, being often corrected for their mistakes such as in pronunciation, and being laughed at by their peers when making mistakes while speaking in front of the class.

The lack of practice in giving oral presentations has also been identified as a cause of language anxiety during such presentations. For example, Mahfoodh's (2014) study on six international undergraduate female students enrolled in a B.A. program in a Malaysian university revealed that when the students were required to deliver an oral presentation, other than facing difficulties in linguistic usage, presentation skills and content preparation, insufficient prior experience in conducting oral academic presentations was also found to be a leading cause among these students.

\section{Methodology}

This study employs a combination of quantitative and qualitative methods; questionnaires and interviews were used to collect the data. The sample of the study consisted of 230 students from the engineering and commerce departments of a polytechnic in Sarawak. They were in their fifth semester and registered in the AE 501 Communicative English course. All of them had given academic oral presentations in previous courses such as AE 101 Communicative English 1 and $A E$ 301 Communicative English 2. They are also required to give oral presentations in their current English course. A decision was made to compare the language anxiety of the engineering and commerce students because the first researcher's observations indicate that the commerce students tend to do better in their oral presentation assessment as compared to the engineering students during their English course even though they are taught by the same lecturer.

The questionnaire was adapted from a study by Nguyen Thi Van (2010). The original questionnaire consisted of two sections. The first section focused on the areas of oral presentation difficulties. There are four constructs in this section: preparation, organisation, delivery and evaluation. The construct "Delivery" is further categorised into sub-constructs such as getting and maintaining audience's attention, body language, language use, time management, anxiety management and handling the audience's questions. The second section focused on the causes of oral presentation difficulties.

Some modifications of the items were done according to the needs of the respondents and comments from the two lecturers who validated the questionnaire. The sentence structures were rephrased or simplified in order to suit the level of 
polytechnic students and ensure that they can understand the items clearly. For example, item 1 "My English proficiency is not high enough" in the second section was rephrased as "My oral English is not proficient enough". For item 8, the phrase "I lack teachers' provision of sample presentations and language for a presentation" was rephrased as "I lack guidance from the teachers on delivering effective oral presentation". Apart from these statements, two items under the construct "Evaluation" in the first section were omitted as the polytechnic students were not required to evaluate their own presentations and their peers' presentations.

A reliability test was conducted on the questionnaire and the Cronbach Alpha reliability coefficients showed a value of 0.94 , which indicates high levels of internal reliability. An Alpha value is considered satisfactory if it is equal to or greater than 0.70 (Pawar \& Thakurdesai, 2013).

On the other hand, the researcher employed interviews in the study in order to further support and explain the quantitative findings. The interviews conducted are a semi-structured type, which consists of questions that elicit information such as respondents' perceptions of the importance of oral presentations and difficulties faced in oral presentations. The interview was conducted in a pre-arranged session with eight students (i.e. four engineering students and four commerce students). The students who participated in the interview were recommended by their English lecturer.

Data obtained from the questionnaire were analysed using SPSS version 20.5. The findings were then computed to obtain means and standard deviations. In addition, an independent sample t-test was conducted to ascertain the differences in difficulties in oral presentation between engineering and commerce students.

Data obtained from the interviews were transcribed and coded into categories. The respondents were identified by the codes assigned to them: ES1 (Engineering student 1), ES2 (Engineering student 2), ES3 (Engineering student 3), ES4 (Engineering student 4), CS1 (Commerce student 1), CS2 (Commerce student 2), CS3 (Commerce student 3) and CS4 (Commerce student 4).

\section{Results}

\section{Areas of Academic Oral Presentation Difficulties}

This part presents the questionnaire and interview findings in determining the main area of difficulty faced by the polytechnic students when giving oral presentations in English.

Table 1 shows that the students' least difficult area of academic oral presentation is preparation, with the lowest mean score of $2.95(S D=0.82)$ and evaluation is not a difficult area too $(M=2.99, S D=1.02)$. The students' most difficult area of academic oral presentation is delivery, with the highest mean score of 3.24 $(S D=0.93)$. 
Table 1

Areas of oral presentation difficulties

\begin{tabular}{lcc}
\hline Areas & M & SD \\
\hline Delivery & 3.24 & 0.93 \\
Organisation & 3.16 & 0.94 \\
Evaluation & 2.99 & 1.02 \\
Preparation & 2.95 & 0.82 \\
\hline Note: $\mathrm{M}$ - Mean, SD - Standard Deviation
\end{tabular}

The area of delivery is further divided into a few sub-areas such as getting and maintaining audience's attention, body language, language use, time management and anxiety management. Table 2 shows that most of the students faced difficulties in language use and anxiety management, with both sharing the highest mean score of 3.41, standard deviations of 0.91 and 0.93 respectively. These two sub-areas of delivery will be focussed on in greater detail.

Table 2

Difficulties in the area of delivery

\begin{tabular}{lcc}
\hline Difficulties & M & SD \\
\hline Language use & 3.41 & 0.91 \\
Anxiety management & 3.41 & 0.93 \\
Time management & 3.30 & 0.90 \\
Handling the audience's questions & 3.25 & 0.90 \\
Getting and maintaining audience's attention & 3.11 & 0.98 \\
Body language & 2.97 & 0.97 \\
\hline
\end{tabular}

Note: $\mathrm{M}$ - Mean, SD - Standard Deviation

In terms of language use, the students did not highlight difficulty in expressing their ideas but instead focussed on difficulties in their pronunciation, as shown by the following excerpts:

The first thing is of course the English itself. The pronunciation. I mean we need to practise more [ES1].

First, my pronunciation is sometimes, sometimes good, sometimes bad [ES2].

Sometimes, with my English pronunciation, and, there's a lot from my pronunciation because my English is not so good [CS3].

Sometimes when I'm presenting, I, not to say lack of confidence but when I want to present, it's just that we have difficulties in pronunciation [CS4].

If the pronunciation is far from what Malaysians are used to hearing, then this might affect comprehensibility. However, if the pronunciation is within the acceptable 
range, the students need not feel overly anxious over their pronunciation during oral presentations.

Besides pronunciation, another aspect of language use mentioned by students in the interviews is proficiency in English. Two interviewees mentioned that they had problems with their English proficiency, which posed a big challenge to them when conducting their oral presentation.

Ok and then second is, I am not very good speaking in English even though I love to, love to hear English songs [ES2].

When how to speak in English correctly, atau combine the words, like if we speak in Malay for example, we know how to speak Malay fluently, but when we want to speak that word in English, we get confused [ES3].

One interviewee mentioned that he had difficulty in elaborating his main points during his presentation. The difficulty arose because the topic of presentation, which had been assigned by his lecturer, was unfamiliar to him.

Second, we don't know how to elaborate our point, main point because sometimes student asks questions, but we don't know what is it about, what the topic we present to them because this topic, certain topic is given by the lecturer. So, we have to explain even though that topic is not required, I mean that topic is not from our self [ES4].

The problems in elaborating main points and handling the audience's questions arise from the student's lack of familiarity with the topic, and the terms needed to talk about it. This problem would be compounded if the topic is more complex and academic.

Other than language use, the students also reported having difficulty with anxiety management when delivering their oral presentations. Three interviewees mentioned that they felt nervous when they were required to conduct an oral presentation. The nervousness caused them to make mistakes in their grammar and forget their ideas when presenting.

I feel nervous, and when I feel nervous I have grammar errors, and... I don't speak well in front of people because of my nervousness [CS1].

And I... when I feel nervous also I have no idea what I'm... what that I'm going to speak [CS1].

The first thing is ... unable to control my nervousness [CS2].

Yes, I face it, because first time it's nervous but then I'm trying to calm down, trying to control it, and then after a few minutes I feel ok and I'll present itpresent well [CS3]. 
The results show that the interviewees' nervousness affected the delivery of their oral presentations.

\section{Differences between Engineering and Commerce Students in Academic Oral Presentation Difficulties}

This part presents the findings on significant differences between engineering and commerce students in their areas of difficulties when giving academic oral presentations.

Using the alpha value of 0.05 , an independent samples t-test was conducted to find out whether there were significant differences between engineering and commerce students in the areas of difficulties in oral presentation. The results of the Levene's test show that $p>0.05$, and this indicates that equal variances have been assumed.

In the area of preparation, the difference between the engineering and commerce students is significant, $t(221)=2.75, p=0.007$. An examination of the group means indicates that the engineering students $(M=2.99, S D=0.51)$ faced more difficulties in preparing for oral presentations than the commerce students ( $M$ $=2.77, S D=0.54$ ).

In the area of organisation, the difference is significant, $t(221)=2.85, p$ $=0.005$. An examination of the group means indicates that the engineering students $(M=3.23, S D=0.66)$ faced more difficulties in organising the content of their presentation than the commerce students $(M=2.93, S D=0.59)$.

In the area of delivery, there is also a significant difference between the two groups of students, $t(221)=2.29, p=0.023$. An examination of the group means indicates that the engineering students $(M=3.22, S D=0.58)$ faced more difficulties in delivery than the commerce students $(M=3.01, S D=0.52)$.

In the area of evaluation, there is no significant difference between the engineering and commerce students, with $t(221)=1.81, p=0.071$. 
Table 3

Independent samples test results on areas of oral presentation difficulties

\begin{tabular}{|c|c|c|c|c|c|c|c|c|c|c|}
\hline & & \multicolumn{2}{|c|}{ Levene's Test } & \multicolumn{7}{|c|}{ t-test for Equality of Means } \\
\hline & & \multirow[t]{2}{*}{ F } & \multirow[t]{2}{*}{ Sig. } & \multirow[t]{2}{*}{$t$} & \multirow[t]{2}{*}{ df } & \multirow[t]{2}{*}{$\begin{array}{l}\text { Sig. (2- } \\
\text { tailed) }\end{array}$} & \multirow[t]{2}{*}{$\begin{array}{c}\text { Mean } \\
\text { Difference }\end{array}$} & \multirow[t]{2}{*}{$\begin{array}{l}\text { Std. Error } \\
\text { Difference }\end{array}$} & \multicolumn{2}{|c|}{$\begin{array}{l}\text { 95\% Confidence Interval o } \\
\text { the Difference }\end{array}$} \\
\hline & & & & & & & & & Lover & Upper \\
\hline \multirow[t]{2}{*}{ Preparation } & $1^{*}$ & 1.332 & 250 & 2.745 & 221 & .007 & .229 & .084 & .065 & .394 \\
\hline & $2 *$ & & & 2.660 & 71.769 & .010 & .229 & .086 & .058 & .402 \\
\hline \multirow[t]{2}{*}{ Organisation } & $1^{*}$ & 1.451 & .230 & 2.849 & 221 & .005 & .299 & 105 & .092 & .505 \\
\hline & $2 *$ & & & 3.038 & 82.222 & .003 & .299 & .098 & .103 & .494 \\
\hline \multirow[t]{2}{*}{ Delivery } & $1^{*}$ & 1.166 & 281 & 2.293 & 221 & .023 & .211 & .092 & .030 & .392 \\
\hline & $2 *$ & & & 2.434 & 81,615 & .017 & 211 & .087 & 038 & .384 \\
\hline \multirow[t]{2}{*}{ Evaluation } & $1^{*}$ & 1.023 & 313 & 1.812 & 221 & 071 & 220 & .121 & -0193 & .459 \\
\hline & $2 *$ & & & 1.776 & 72.825 & .080 & .220 & .124 & -0269 & .467 \\
\hline
\end{tabular}

- 1 Equal variances assumed

$* 2$ Equal varlances not assumed 
The results of the independent sample t-tests show that there are a number of significant differences between engineering and commerce students in the areas of oral presentation difficulties, except for the area of evaluation. The engineering students found preparation for the oral presentation more difficult than the commerce students; this is probably because the former focussed more on their core courses, especially their engineering subjects, which involved project work that required much time and effort. They tended to copy the points obtained from the internet and pasted them in the slides in order to reduce their own burden. This resulted in the students' inability to explain the information in their slides during their oral presentations. Besides, they might worry about getting low marks in their oral presentation assessments due to their poor communication skills in English and started to have negative thoughts that affected their level of confidence. This condition appeared to be closely related to "test anxiety" (Horwitz \& Young, as cited in Joy, 2013, p. 2). In addition, engineering students generally prefer practical tasks such as hands-on activities rather than oral presentations.

In addition to the area of preparation, the engineering students also faced greater difficulties in the organisation area as compared to the commerce students. Based on the researcher's years of experience in conducting oral presentation assessments at the polytechnic, engineering students tend to merely highlight the salient points from an article, then copy and paste the points onto the PowerPoint Slides. Therefore, their presentations appear disorganised and they have trouble elaborating their points.

\section{Discussion}

Based on the questionnaire and interview results, anxiety is the most difficult aspect of delivering an oral presentation for most participants. They felt nervous when delivering their oral presentations and the nervous affected their performance. Nervousness is one of the psychological factors that affect the students' presentation skills, which hinders them from delivering their presentations effectively. In other words, the audience anxiety leads to "fear, tension and [they become] disorganised in front of an audience" (Buss, as cited in McCroskey, 2010, p. 146). Similar findings on anxiety during oral presentations were obtained by other researchers (Chen, 2009; Kakepoto, Habil Omar \& Said, 2012; Mahfoodh, 2014). A possible reason for the nervousness is their fear of negative evaluation; they are too concerned "about being judged despairingly or hostilely by others" (Carleton et al., 2006, p. 297). They might have assumed that the audience expects their presentation to be perfectly delivered or they will be laughed at when making mistakes while speaking in front of the class. Other factors that cause the students to be nervous when presenting orally are fear of being the centre of attention as well as audience characteristics like size, status, similarity and formality (The University of Southern Mississippi, 2014).

The second difficulty encountered by the students in their oral presentations is language usage. Most students stated that they tended to make grammatical errors and felt that they were unable to use appropriate vocabulary and sentence structure when presenting. Two students mentioned in their interviews that they 
were not able to speak English as fluently as Malay or their mother tongues. Elsewhee, El Enein (2011), Mahfoodh (2014) and Nguyen Thi Van (2010) also found that students who faced linguistic difficulties such as oral proficiency, fluency and lack of vocabulary and structures would be constrained in expressing their complex concepts and ideas when they were giving oral academic presentations. Thus, the students became highly apprehensive when they were required to deliver their presentation in English, and this emotion affected their performance. This situation has been known as "oral communication apprehension" (McCroskey, 1977, p.78).

Also contributing to the oral communication comprehension is the students' perception of their inability to deliver their presentation with clear pronunciations (in terms of sound, words, sentence structure and stress). In the interview, four students said that they had difficulty in pronunciation. According to Nguyen Thi Van (2010), unclear pronunciation would make it difficult for the students' presentations to be understood well. Problems in pronouncing English words probably stem from the influence of the students' non- English mother tongue. According to Avery and Ehrlich (as cited in Gilakjani \& Ahmadi, 2011, p. 78):

the sound pattern of the learner's first language is transferred into the second language and is likely to cause foreign accents. [Hence], the mispronunciations of words by non-native speakers reflect the influence of the sounds, rules, stress, and intonation of their native language.

In the area of delivery, the results support the findings of Habil, and $\mathrm{Ab}$ Rahman (2010) that even though the engineering students were aware of the oral presentation delivery skills, they did not use appropriate delivery skills when giving oral presentations. This is probably due to a lack of practice and nervousness, especially when they were required to present in front of their lecturer or peers.

\section{Conclusion}

This study has identified the polytechnic students' areas of difficulties in delivering oral presentations in English The findings from this study show that delivery is the most challenging area for students in giving oral presentations in English. This study has its limitation; it covers only the oral presentation difficulties encountered by students in a polytechnic in Sarawak. Further research on students from other polytechnics in Malaysia would lead to a better understanding of the common difficulties of students in skill-based academic programmes so that the teaching of communication skills becomes more relevant to meet their needs.

\section{References}

Abdullah, K. I., \& Abdul Rahman, N. L. (2010). A study on second language speaking anxiety among UTM students. http://eprints.utm.my/10275/

Carleton, N., McCreary, D., Norton, P., \& Asmundson, G. (2006). Brief fear of negative evaluation scale revised. Depression and Anxiety, 23, 297-303. 
Chen, L.Y. (2009). A study of EFL graduate students' oral presentation anxiety (Unpublished Master's thesis, National Chung Cheng University).

Chen, W. C. D. (2009). A pilot study of some ROCMA cadets' difficulties in English speaking. WHAMPOA - An Interdisciplinary Journal, 57: 119-126.

Curriculum Department and Evaluation Division (2011). Syllabus for AE501 Communicative English 3. Department of Polytechnic Education, Ministry of Higher Education, Malaysia.

El Enein, A. H. A. (2011). Difficulties encountering English majors in giving academic oral presentations during class at Al-Aqsa University (Unpublished Master's thesis, Islamic University of Gaza).

Gilakjani, A. P., \& Ahmadi, M. R. (2011). Why is pronunciation so difficult to learn? English Language Teaching, 4(3), 74-83.

Habil, H., \& Ab Rahman, N. A. (2010). An investigation of engineering students' oral presentation delivery skills: A case study. Retrieved from http://eprints.utm.my/11537/

Hanafi Zaid, Y., \& Kamarudin, H. (2011). Oral communication needs of Mechanical Engineering undergraduate students in UTM as perceived by the learners. Retrieved from http://eprints.utm.my/11755/1/Oral_Communication_Needs_Of_Mechanica I_Engineering_Undergraduate_Students_In_UTM.pdf

Horwitz, E. K., Horwitz, M. B., \& Cope, J. (1986). Foreign language classroom anxiety. The Modern language journal, 70(2), 125-132.

Joy, J. L. (2013). The altitude of test anxiety among second language learners. Language Testing in Asia, 3(1), 1-8.

Kakepoto, I., Habil, H., Omar, N. A. M., \& Said, H. (2012). Factors that influence oral presentations of engineering students of Pakistan for workplace environment. Information \& Knowledge Management, 2(7), 70-78. Retrieved from http://www.iiste.org/Journals/index.php/IKM/article/viewFile/3259/3531

King, J. (2002). Preparing EFL learners for oral presentations. The Internet TESL Journal, 8(3). Retrieved from http://iteslj.org/Lessons/KingPublicSpeaking.html

Mahfoodh, O. H. A. (2014). Oral academic discourse socialisation: Challenges faced by international undergraduate students in a Malaysian public university. International Education Studies, 7(2), 10-17.

McCroskey, J. C. (1977). Oral communication apprehension: A summary of recent theory and research. Human communication research, 4(1), 78-96.

McCroskey, J. C. (2010). Oral communication apprehension: A reconceptualization. Communication Yearbook 6, (6), 136.

Nguyen Thi Van, H. (2010). A study on oral presentation difficulties of Second-Year English Majors of Phuong Dong University in the speaking lessons and solutions (Unpublished Master's thesis, Vietnam National University).

Pawar, S. S., \& Thakurdesai, P. A. (2013). Translation and validation of Hindi version of the multidimensional questionnaire (MDQ) for quality of life assessment in type 2 Diabetes Mellitus patients in Indian population. International Journal of Pharmaceutical Sciences and Research, 4(5), 1827-1832. 
Singh, M. K. M., \& Chua, J. S. C. (2012). Manufacturing industry employers' perception of graduates' English language skills proficiency. International Journal of Applied Linguistics \& English Literature, 1(4), 114-124.

ijuThe University of Southern Mississippi (2014). Speaking anxiety. Retrieved August 18, 2014, from http://www.usm.edu/gulfcoast/sites/usm.edu.gulfcoast/files/groups/learni ng-commons/pdf/speech_anxiety_web.pdf

Yusoff, M. (2010). Analysing communication competence in oral presentations: Engineering students' experiences. Journal of Human Capital Development, 3(1), 99-118.

Zainuddin, Z. A. A., \& Selamat, S. (2012). Efficacy of polytechnic students' interpersonal communication skills. Advances in Language and Literary Studies, 3(2), 76-86. 